\title{
A'prenda' e o voto: as primeiras participações femininas nas eleições do Rio Grande do Sul (1933-1935)'
}

\author{
The prenda' and the vote: the early insertions in the women's \\ Rio Grande do Sul elections (1933-1935)
}

La prendá y el voto: las primeras elecciones con la participación de las mujeres en

Rio Grande do Sul (1933-1935)

Mônica Karawejczyk*

\section{Resumo}

Este artigo pretende destacar a participação feminina das gaúchas nas três primeiras eleições da República Nova, na década de 1930. Mais do que apontar a inédita participação das cidadãs do Rio Grande do Sul no pleito eleitoral, este artigo quer destacar a efetiva participação política das mulheres na época. Para tanto, procura dados nos principais jornais editados em Porto Alegre, no período analisado, a saber, Correio do Povo, Diário de Notícias, Jornal da Manhã e A Federação.

Palavras-chave: Eleições. Imprensa. Mulheres.

\section{Introdução}

Nos dias atuais é difícil imaginar que o simples ato de uma mulher comparecer a uma seção eleitoral já foi considerado um absurdo. Apesar de a historiografia vincular o termo "universal" ao tipo de sufrágio que se estabeleceu em 1848, na França, quando a exigência monetária para ser eleitor foi abolida, o sufrágio universal de fato, com igualdade de voto para homens e mulheres, só foi Doutora em História pela Universidade Federal do
Rio Grande do Sul, Brasil. Professora colaborado-
ra no Programa de Pós-Graduação em História da
Pontifícia Universidade Católica do Rio Grande do
Sul, Brasil.

Recebido em 01/04/2016 - Aprovado em 01/09/2016

http://dx.doi.org/10.5335/hdtv.16n.2.6931 
conquistado nas primeiras décadas do século XX. Nesse sentido, o Brasil figura como um dos pioneiros na concessão do voto para as mulheres na América Latina.

Ao assumir a chefia do governo provisório, Getúlio Vargas designou, pelo Decreto $\mathrm{n}^{\circ} 19.459$, de 6 de dezembro de 1930, uma subcomissão legislativa para estudar e propor a reforma da lei e do processo eleitoral. Uma das reformas propostas consistia em estender o direito de voto às mulheres, reconhecido com a publicação do novo Código Eleitoral, pelo Decreto ${ }^{\circ}$ 21.076, de 24 de fevereiro de 1932. A redação do artigo $2^{\circ}$ determinou: é eleitor o cidadão maior de 21 anos, sem distinção de sexo, alistado na forma deste Código (KARAWEJCZYK, 2013, p. 298-299).

A conquista do voto feminino fez parte de uma longa luta pela cidadania no Brasil. José Murilo de Carvalho indica que

[...] não houve no Brasil, até 1930, movimentos populares exigindo maior participação eleitoral. A única exceção foi o movimento pelo voto feminino, valente, mas limitado (CARVALHO, 2004, p. 42).

Apesar de reconhecer a importância do movimento sufragista brasileiro, o autor, ao caracterizá-lo denominá-lo como limitado, acaba não percebendo a sutileza de um movimento que fez parte de um interesse específico das mulheres que, como um grupo organizado, tinha uma demanda própria na época: o reconhecimento da sua cidadania por meio do direito de votar e de ser votada. A busca pela igualdade de tratamento entre homens e mulheres, por meio de reformas legislativas, foi percebida, naquele momento, como as mais capazes de garantir às mu- lheres o acesso ao espaço público e à plena cidadania. As mulheres que fizeram parte do movimento, tanto na Europa como no Brasil, foram, de modo geral, parte

[...] de uma vanguarda, mais ou menos audaciosa, de mulheres empenhadas na vida ativa, instruídas, oriundas da pequena e média burguesia (ARNAUD-DUC, 1991, p. 100).

Não obstante a importância do movimento sufragista na história brasileira, pouco se conhece da sua trajetória e dos personagens que fizeram parte dessa luta. Não conhecemos essas mulheres, nossos livros didáticos não as mencionam, tampouco sua luta. Uma das causas desse desconhecimento pode ser creditada à maneira como a história ocidental tem sido escrita, segundo Joan Scott:

[...] desde que na moderna historiografia ocidental, o sujeito tem sido incorporado com muito mais frequência como um homem branco, [...] reivindicar a importância das mulheres na história significa necessariamente ir contra as definições de história e seus agentes já estabelecidos como 'verdadeiros', ou pelo menos, como reflexões acuradas sobre o que aconteceu (ou teve importância) no passado (SCOTT, 1992, p. 77).

Nesse mesmo viés interpretativo estão as ponderações de Maria Lygia Quartim de Moraes que afirma:

Ao longo da história do Brasil as mulheres não permaneceram omissas ou passivas. $\mathrm{Na}$ verdade, os estudos sobre a condição feminina realizados nas últimas décadas demonstram que, com relação a esse assunto, tratou-se menos de um silêncio por parte das mulheres do que do silêncio por 
parte da historiografia, seja devido à inexistência da documentação, à dificuldade de acesso a documentos manuscritos ou ainda à falta de interesse (que prevaleceu por um longo tempo), por parte dos pesquisadores, em encarar a questão (MORAES, 2003, p. 506).

De modo semelhante, a esfera política e pública foi, durante muito tempo, vetada às mulheres, que eram vistas nesse espaço com estranheza e desconfiança. Levando-se em conta tais ponderações, parece que as mulheres estavam fora da história oficial mais por falta de interesse de se contar sua história do que por falta de uma participação efetiva feminina na sociedade. Esse também é o caso das mulheres do estado mais meridional do Brasil, o Rio Grande do Sul.

A historiografia muitas vezes descreve o Rio Grande do Sul como periférico e conservador. Fábio Kühn acentua que

[...] durante a República Nova [...]. O governo federal via o estado como destinado a complementar a economia central como fornecedor de gêneros de subsistência para o mercado nacional (2004, p. 125).

Essa também é a constatação a que chega Sandra Pesavento ao afirmar que durante esse período

[...] o governo da União via o Rio Grande do Sul como destinado a complementar a economia central em seu papel fornecedor de gêneros de subsistência para o mercado consumidor nacional (2002, p. 106).

Áurea Petersen, descrevendo o mesmo período, salienta outro aspecto importante que deve ser levado em consideração:
[...] a sociedade riograndense é marcadamente patriarcal, do que decorre o estrito controle da mulher. Além disso, o Rio Grande do Sul viveu, a partir da Proclamação da República, sob a influência do positivismo, para o qual a mulher é a 'guardiã do lar' e 'anjo protetor' da família (1999, p. 8).

Por essas descrições parece que o "ambiente" no estado não estimularia a participação da mulher fora do eixo familiar. Contudo, apesar de poder ser considerado um estado periférico em relação à economia, o mesmo não se poderia dizer em relação à cultura e à política. Charles Monteiro, ao retratar a mesma época das pesquisas citadas anteriormente demonstrou que o:

Estado do Rio Grande do Sul, foi favorecido pela guerra [Primeira Guerra Mundial] e pelo crescimento da indústria nacional, que impulsionou o desenvolvimento [...] regional. As ligações de Porto Alegre com o centro do país foram incrementadas por via rodoviária e aérea, com linhas regulares ligando Porto Alegre ao Rio de Janeiro e a São Paulo, mas também por meio de ligações ferroviárias - que se estendem para o interior do Estado - e marítimas que por meio do porto de Rio Grande ligavam o Estado com todo o Brasil e o exterior. [...] Porto Alegre deixou de ser uma cidade provinciana e isolada no extremo Sul do Brasil, para tornar-se uma metrópole moderna em contato com o centro do país e o exterior (2006, p. 37, 39).

Elizabeth Torresini, por sua vez, enumerou as vantagens de se produzir livros no estado mais austral do Brasil, na década de 1930, da seguinte forma: 
Apesar dessa distância [em relação ao centro do poder político] e mesmo por esta razão, o Rio Grande do Sul transforma-se no terceiro centro industrial da Federação. Aqui as condições para o desenvolvimento de uma empresa industrial voltada aos livros também são favoráveis por que: $1^{\circ}$ trata-se de um estado cuja tradição industrial está bastante definida, pelas suas necessidades de abastecimento, e tem Porto Alegre como principal pólo produtor; $2^{\circ} \mathrm{o}$ Rio Grande do Sul, segundo fontes oficiais, é o estado que possui a maior taxa de indivíduos alfabetizados do Brasil, o que significa, entre outras coisas, a existência de virtuais leitores [...] $4^{\circ}$ Porto Alegre é um importante centro cultural que abriga intelectuais atuantes (1988, p. 152).

Tais pesquisas apontam que o Rio Grande do Sul, na década de 1930, era caracterizado por ser um importante centro cultural, com uma efervescente vida política, que não podia ser relegado a um papel secundário e periférico. Também é interessante acentuar que, na época em questão, havia um bom número de periódicos circulando no estado, e que eram os principais meios (quando não o único) utilizados pela população para se informar sobre o que acontecia no Brasil e no mundo (RUDIGER, 1993; SILVA; CLEMENTE; BARBOSA, 1986).

Quanto à questão da inserção feminina no pleito eleitoral, desde meados do século XIX, já ocorriam no Brasil manifestações isoladas em prol do direito de voto para a mulher. Nesse sentido pode-se citar o caso de Isabel de Sousa Matos, dentista que, baseada na Lei Saraiva, teria conseguido alistar-se para votar na Província do Rio Grande do Sul. em 1885. ${ }^{2}$ Entretanto, a luta pelo direito ao voto feminino só tomou uma direção mais definitiva entre as décadas de
1910 e 1920, com o aparecimento no Rio de Janeiro de duas associações femininas. A primeira delas, Partido Republicano Feminino, foi fundada em 1910 pela professora Leolinda de Figueiredo Daltro. A segunda, a Liga pela Emancipação Intelectual da Mulher, surgiu em 1920, foi rebatizada em 1922 como Federação Brasileira pelo Progresso Feminino, tendo Bertha Lutz como responsável pela sua fundação. A partir de então as brasileiras passaram a se organizar de uma forma mais sistematizada na busca pelos seus direitos políticos, promovendo passeatas, escrevendo para jornais, pressionando os políticos a atender suas demandas bem como promovendo reuniões e conferências para discutir seus problemas. Nos quadros de sócias de ambas as associações, pode-se encontrar o nome de muitas mulheres nascidas no Rio Grande do Sul. ${ }^{3}$

No Parlamento brasileiro, de 1917 a 1925, foram apresentadas cinco propostas de lei e/ou emendas parlamentares para incluir as brasileiras no quesito eleitor. Apesar de nenhuma ter sido aprovada, o fato mostra que a questão era um tema candente no Congresso Nacional, na época. Em 25 de outubro de 1927, o estado do Rio Grande do Norte aprovou lei que permitiu o alistamento feminino estadual. Assim, o direito de voto foi garantido para as mulheres pela primeira vez no país, embora sem alcance nacional. Com o advento da Revolução de 1930, grande parte da legislação anterior foi renovada e o direito ao voto feminino foi concedido a todas brasileiras com a elaboração de novo Código Eleitoral, em 1932. Mas, e o Rio Grande do Sul? 
Após a conquista do sufrágio feminino, como foi a participação das suas mulheres no pleito eleitoral? Os poucos registros que sobraram relativos à questão específica da inserção feminina no quesito eleitor estão restritos quase que unicamente à imprensa diária, que acompanhava o dia a dia das cidades, destacando os fatos inusitados e noticiando as principais demandas sociais, o que motivou o uso seu como fonte. ${ }^{4}$

\section{A participação feminina nas eleições - "estreia auspiciosa"}

A inédita participação feminina nas eleições, em todo o Brasil, deu-se no dia 3 de maio de 1933. Palavras como "vibrante demonstração de civismo", "perfeita ordem" e "empolgante pleito" foram utilizadas pelos jornais para descrever as eleições de um modo geral. A participação feminina foi descrita tanto como "pitoresca" quanto "entusiasmada". De acordo com o que foi publicado nos jornais, ao menos seis mulheres estavam concorrendo a um dos cargos de deputados naquele pleito, cinco delas pela capital federal - Bertha Lutz, Ilka Labarthe, Georgina de Azevedo Lima, Leolinda de Figueiredo Daltro e Natércia da Silveira (advogada nascida no Rio Grande do Sul) - e uma por São Paulo, a médica Carlota Pereira de Queiroz, única eleita.

O pleito fora convocado para preencher as 214 vagas de deputados constituintes que participariam da elaboração nova Carta Constitucional do país. Em todo o território nacional, 802 cidadãos candidataram-se a uma dessas vagas. Pelo Rio Grande do Sul, 36 candidatos disputaram uma das
16 vagas que pertenciam ao estado (NOLL; TRINDADE, 2004, p. 73)..$^{5}$ O número de eleitores inscritos em todo o país foi noticiado como sendo de 1.284.904, desses, 77.369 no Rio Grande do Sul (CORREIO DO POVO, 1933, p. 1). Porto Alegre contou com três zonas eleitorais, totalizando 24.256 pessoas alistadas e aptas para votar nas eleições (CORREIO DO POVO, 1933, p. 4). O número de mulheres alistadas na capital dos gaúchos foi assim divulgado:

Em Porto Alegre o eleitorado feminino atinge a um total de 4.000 , ou sejam, cerca de $20 \%$ sobre o eleitorado da capital. As eleitoras, na maioria, são professoras, funcionárias públicas que, em grande número, exerce a sua atividade nas repartições locais (CORREIO DO POVO, 1933, p. 8).

Tal percentagem parece apontar para uma expressiva participação feminina no pleito eleitoral. No interior do estado, a percentagem de mulheres alistadas foi ainda maior. O Diário de Notícias aponta que tanto em Santa Cruz do Sul quanto em Cachoeira, ${ }^{6}$ $30 \%$ dos que compareceram para votar eram mulheres (DIÁRIO DE NOTÍCIAS, 1933, p. 3, 5). Por sua vez, A Federação (12 maio 1933, p. 1) e o Jornal da Manhã (13 maio 1933, p. 10) deram ênfase à grande participação feminina na cidade de Nova Vicenza (atual Farroupilha), que participava com $34 \%$ do eleitorado total. Levando-se em conta tais dados, percebe-se que a participação das gaúchas nessa eleição foi expressiva, ainda mais considerando que o alistamento feminino era optativo e era a primeira vez que as brasileiras participaram do pleito eleitoral no país.

O Correio do Povo e o Diário de Notícias foram os jornais que dedicaram mais espaço 
às eleições federais. O Jornal da Manhã, quando noticiou o pleito, quase não fez menções à participação feminina, muitas vezes, apenas mencionando que "ambos os sexos" compareceram ao pleito. Contudo, o jornal publicou fotografias retratando o eleitorado feminino. A única menção encontrada em $A$ Federação sobre a participação das gaúchas foi a publicação de uma foto de uma senhora com a seguinte legenda: "A neve dos anos não arrefeceu antes reacendeu de novo o entusiasmo, o ardor patriótico...". ${ }^{7}$

Um ponto que merece destaque na análise dos jornais foi de que, no geral, todos dedicaram muito mais espaço nas suas publicações para as eleições em outros estados da federação, em especial para a Capital Federal (RJ), do que para a ocorrida no Rio Grande do Sul e sua capital, Porto Alegre. Das 34 matérias selecionadas no Correio do Povo, por exemplo, apenas sete faziam referência ao Rio Grande do Sul e duas a Porto Alegre. O Jornal da Manhã não publicou uma única linha sobre a participação feminina no pleito de Porto Alegre e no Diário de Notícias, das 57 matérias encontradas sobre esse pleito eleitoral, apenas quatro tratavam sobre Porto Alegre, o mesmo ocorrendo n'A Federação. Outro fator que chamou a atenção na análise dessas matérias foi a escolha das palavras para descrever a inédita participação da mulher no pleito, entre as quais destacam-se: ordem, alegria, moralidade e resignação. Tal escolha parece reforçar a ideia vigente na época de que a inserção feminina no pleito eleitoral traria moralidade para o mundo político, regenerando a vida pública do país, como indica esta matéria que comenta a eleição na cidade de Pelotas:
[...] a impressão unânime é de que nunca houve, aqui, um pleito tão calmo, sem atropelos, nem irregularidades. [...] muito influenciou a presença de senhoras e senhoritas da nossa melhor sociedade, cuja ocorrência às urnas foi grande (Diário de Notícias, 5 maio 1933, p. 1).

O Jornal da manhã apesar de não publicar nenhum texto sobre a participação das porto-alegrenses no pleito, deu visibilidade ao tema ao relatar como se procederam as eleições em outros estados da federação, tal como no Rio de Janeiro, onde "o eleitorado feminino [...] está se apresentando em massa, dando-se dessa maneira uma estreia auspiciosa do voto feminino no Brasil" (5 maio 1933, p. 8).

Quase todas as imagens escolhidas pelos jornais para retratar a primeira participação feminina no pleito, com exceção de uma publicada no Correio do Povo, mostram mulheres idosas, em poses deselegantes, o que não estaria relacionado ao tradicional ato de votar. Pode-se questionar o porquê da opção por tais imagens, uma vez que todos os periódicos afirmaram que a participação feminina nas eleições havia sido expressiva. Ao não querer salientar em imagens a participação de mulheres jovens, os jornais talvez estivessem reforçando mais uma das muitas imagens recorrentes na época, que associava qualquer interesse em política com mulheres feias, velhas, sem atrativos e sem família.

A próxima eleição a que as brasileiras compareceram ocorreu no dia 14 de outubro de 1934. Foi convocada para prover os cargos de deputado das Assembleias Estaduais Constituintes e para deputado federal. ${ }^{8} \mathrm{O}$ governo provisório havia acabado em julho, com a promulgação da nova Carta Constitu- 
cional e a eleição indireta de Getúlio Vargas para o cargo de presidente da República. Naquela eleição, o Rio Grande do Sul tinha direito a ocupar 20 cadeiras na Câmara Federal e 32 na Câmara Estadual. ${ }^{9}$

A campanha eleitoral de 1934 no Rio Grande do Sul, diferenciou bastante da anterior, pela violência perpetrada, principalmente, por Flores da Cunha (interventor do estado desde novembro de 1930). ${ }^{10}$ Segundo a descrição de Cortés:

Ao contrário da razoavelmente tranquila eleição de 1933, a de 1934 foi marcada pela violência. Flores respondeu a campanha de ódio da FU [Frente Única] com a campanha do terror, levada a cabo por seus prefeitos, pela polícia, pelos chefes políticos locais, por oficiais da Brigada Militar e por uma Ação de Resistência Nacional, uma organização civil-militar pró-Flores [...]. Recorreu-se a vários tipos de coerções: a prisão e o exílio dos líderes da FU; atos contra jornais e jornalistas da oposição; 'aposentadorias' compulsórias ou transferência de funcionários públicos, ferroviários e oficiais da Brigada que se recusassem a assinar os manifestos em favor de Flores; intimidação, violência e até assassinatos para evitar que os frentistas fizessem campanha e comparecessem as eleições (2007, p. 105).

Um aspecto que se salientou na análise das matérias publicadas sobre a eleição estadual foi que todos os jornais noticiaram a participação da mulher sul-rio-grandense nas caravanas e comícios eleitorais que percorreram o interior do estado bem como a criação de alas femininas nos principais partidos políticos que concorreram nas eleições gaúchas: o Centro Cívico Liberal Feminino, a Ala Feminina da Ação da Resistência Nacional, o Grêmio Feminino Liberal Evarista
Flores da Cunha. havia ainda os comitês femininos pró-Frente Única, tanto na capital quanto no interior, bem seções femininas e universitárias organizadas pelos integralistas. Esse dado parece sinalizar que algumas gaúchas participariam mais efetivamente no mundo político recém-aberto para elas. Como se sabe, participação política não se resume a comparecer umas poucas horas, a cada ano ou mais, em uma seção eleitoral e depositar seu voto na urna, em seu sentido mais amplo, pode ser entendida como:

[...] o ato do voto, a militância num partido político, a participação em manifestações, a contribuição para uma certa agremiação política, a discussão de acontecimentos políticos, a participação em um comício ou numa reunião de seção, o apoio a um determinado candidato no decorrer da campanha eleitoral, a pressão exercida sobre um dirigente político, a difusão de informações políticas e por aí além (SANI, 2000, p. 888).

Apesar de não ser possível precisar o número de mulheres envolvidas nessas alas e grêmios, sua criação aponta para essa conclusão e sugere que havia uma efetiva presença feminina nos principais partidos políticos que disputaram as eleições no ano de 1934. Nesse sentido, o Jornal da Manhã deu mais destaque em suas edições à atuação dos grêmios femininos do que noticiou outros acontecimentos relativos à participação das gaúchas no pleito eleitoral, dando destaque para a participação das "gentis patrícias, ardorosas adeptas do PRL" (JORNAL DA MANHÃ, 1934, p. 7).

Outro aspecto interessante foi que Porto Alegre teve sua primeira candidata a deputada estadual naquele ano, seu nome era 
Aurora Nunes Wagner e ela participou do pleito concorrendo pela Ação Integralista Brasileira. ${ }^{11}$ Somente dois jornais noticiaram essa inédita candidatura feminina, e o Diário de Notícias e o Jornal da Manhã, apesar de trazerem matérias sobre os integralistas, não fizeram uma única menção à candidatura de Aurora. ${ }^{12} \mathrm{O}$ Correio do Povo escolheu dar a notícia de tal candidatura, publicando um manifesto escrito pela integralista, do qual destaca-se o trecho inicial:

Minhas patrícias! Candidata da Ação Integralista Brasileira à deputação à Assembleia Constituinte do Rio Grande do Sul, venho dizer-vos o significado da aceitação da minha candidatura e dirigir-vos um apelo em prol da campanha nobre e patriótica em que nos empenhamos. Antes de mais nada, cumpre dizer-vos que a candidatura do Integralismo às eleições é somente um meio de propaganda, pois combatemos a política partidária que desune as famílias, atiça a fogueira dos ódios [...]. Visamos com nossas candidaturas justamente a oportunidade para chamar a vossa atenção para esse exercício de "camisas verdes" que corporificam a ideia nova de um Brasil melhor (6 out. 1934, p. 12).

Pela leitura dessas linhas parece ser correto apontar que os integralistas em geral, e a candidatura de Aurora em particular, não almejavam alcançar algum cargo, mas dar visibilidade às bandeiras do integralismo. De modo que no sentido da propaganda dos ideais integralistas, melhor se compreende que, no decorrer do seu manifesto, Aurora tenha aproveitado para expor o que apontou ser "o verdadeiro papel da mulher na sociedade", tal como podermos acompanhar em outro trecho:
Entende o Integralismo que o papel da mulher - na sua maioria - é o de mãe. E a mãe deve ficar no lar, na tarefa sublime da educação dos filhos. [...] É necessário que o governo promova o bem estar das famílias; assegure a possibilidade de trabalho honrado e educação profissional das mulheres. Esse é o supremo interesse do nosso sexo. A 'Ação Integralista Brasileira' é legítima defensora dos nossos interesses (CORREIO DO POVO, 1934, p. 12).

A primeira mulher a se candidatar a um cargo eletivo na cidade de Porto Alegre vinculou-se a um partido que pregava que o lugar da mulher era o lar, cuidando dos filhos e do marido. Entretanto, essa não era a única função da mulher nessa "doutrina", pois tal como acentua Renata Duarte Simões:

[...] o integralismo, [...] vislumbrando as mudanças que ocorriam na estrutura familiar e social, investia no discurso de 'elevação e sublimação' do papel da mulher como mãe e educadora. Diante das manifestações e mudanças sociais que aconteciam no País, a AIB buscou convocar as brasileiras para reassumir, segundo ideais do movimento, os seus deveres (2011, p. 3).

A autora também aponta que "as integralistas atuavam no campo da propaganda e divulgação da doutrina como também no trabalho de assistencialismo junto às famílias pobres" bem como em atividades do setor de medicina preventiva e de educação sanitária (SIMÕES, 2011, p. 6) $\cdot{ }^{13}$ Apesar da votação de Aurora não ter sido muito expressiva, uma vez que conseguiu angariar apenas 716 votos, esse número não se diferenciou muito da quantidade de votos arrecadados por seus companheiros de chapa, todos homens, que também obtiveram essa mesma média de desempenho nas urnas (A FEDERAÇÃO, 1934, p. 2). 
Se a candidatura de Aurora não provocou muito impacto nos jornais porto-alegrenses, a participação feminina no dia da eleição recebeu um bom destaque. Até mesmo pela peculiaridade de que, nesse pleito, a maioria das eleitoras da capital foi designada para votar em seções exclusivamente femininas. Tais seções estavam localizadas em três pontos:

[...] na primeira zona, em nove seções instaladas na Faculdade de Medicina; as da segunda zona, em três seções que funcionarão, uma na União de Moços Católicos da Glória, uma no Colégio Paroquial do Menino Deus e uma na Sociedade Espírita Dias da Cruz. As da terceira zona exercerão o voto em duas secções localizadas no Colégio Elementar Voluntários da Pátria. Ao todo, como se vê, são em número de 14 as seções em que votarão as eleitoras porto alegrenses (CORREIO DO POVO, 1934, p. 16).

Essas seções exclusivas geraram "episódios interessantes", segundo a denominação dos jornalistas que cobriram as eleições. O Jornal da Manhã, por exemplo, publicou uma matéria de capa destacando, classificada de "feminismo disciplinado", a participação feminina no pleito:

A mulher porto alegrense compareceu disciplinadamente as urnas, em diversas seções eleitorais, concentrando-se, porém, nas Faculdades de Medicina, Direito e Engenharia. Grande quantidade de eleitoras, pertencentes a todos os partidos, ali se comprimiram desde as primeiras horas, cumprindo o dever patriótico. Quando visitamos tais colégios eleitorais notamos normalmente, sob um ambiente de graça e de beleza. Diversos episódios interessantes ali registravam. Em determinada secção da Faculdade de Medicina anotamos um flagrante sugestivo: a sala estava quase vazia. Eram 5 horas da tarde. Um cidadão, já idoso, segurava uma criança [...]. A sua esposa fora atender à chamada para votar (JORNAL DA MANHÃA, 1934, p. 1).

De modo semelhante, o Diário de Notícias descreveu a participação feminina como dando "um ar de respeito entre os votantes", mais uma vez associando a ideia de que mulheres nas sessões eleitorais trariam ordem ao ambiente. Todos os jornais destacaram a ordem na votação em Porto Alegre, talvez para diferenciar dos eventos no interior do estado, onde se verificou brigas entre os eleitores e distúrbios generalizados. O Correio do Povo destacou:

[...] a cidade apresentava um aspecto fora do comum. Eram homens e mulheres, de todas as idades e posições sociais que se dirigiam às respectivas secções eleitorais. Notava-se em cada um dos eleitores o interesse em exercer o seu dever cívico. E, esse contínuo vai-vem a todas as mesas eleitorais se prolongou até o escurecer (CORREIO DO POVO, 1934, p. 8).

O eleitorado total de Porto Alegre foi noticiado como sendo de 34 mil eleitores, desses, cerca de 2.800 mulheres se alistaram, o que, segundo o Correio é um número superior ao pleito efetuado em 1933 para deputados à Constituinte Federal (CORREIO DO POVO, 1934, p. 1). ${ }^{14}$ A presença feminina no pleito ainda era destacada como mantenedora da ordem e moralizadora das eleições, mas de forma menos acentuada do que na eleição de 1933. Destaca-se que imagens de mulheres no ato de votar já começam a aparecer nos jornais em 1934, o que pode assinalar que a participação feminina no mundo político começava a ser percebida como legí- 
tima pelos detentores dos meios de comunicação da capital.

A terceira e última eleição da qual as brasileiras tomaram parte na década de 1930 ocorreu em 17 de outubro de 1935. As eleições municipais foram conclamadas para suprir cargos de prefeito e vereadores e a participação feminina já não se constituía uma novidade, o que talvez justifique o fato de que o número de mulheres inscritas para votar nas eleições municipais em Porto Alegre não foi informado em nenhum dos periódicos consultados.

Todos os periódicos enfatizaram mais as notícias do pleito ocorridas no interior do estado do que as ocorridas na capital, Porto Alegre, mesmo sendo uma eleição municipal. Na capital do Rio Grande do Sul não houve eleição para prefeito, pois segundo a nova Constituição estadual, ele seria nomeado pelo governador. Na ocasião, Alberto Bins foi reconduzido ao cargo de prefeito de Porto Alegre, posição que ocupava desde 1928. Na eleição de 1935, 36 candidatos disputaram as nove vagas a vereadores para a cidade de Porto Alegre. Mais uma vez os periódicos destacaram a participação feminina nos comícios políticos do Partido Republicano Liberal, da Frente Única e dos integralistas, nos atos políticos bem como o apoio explícito aos candidatos a vereador, divulgando manifestos, proferindo discursos e participando dos grêmios, alas e seções femininas dos partidos. Todos os jornais divulgaram amplamente a participação das gaúchas em várias de suas edições, dando destaque especial para as cidades de Rio Pardo, Uruguaiana, Bagé, Estrela, Camaquã, Quaraí, dentre outras localidades do interior do Rio Grande do Sul. Um número considerável de mulheres participou das eleições, como candidatas a vereador, no interior do estado, tais como em Santiago do Boqueirão, Cruz Alta, Estrela, Pinheiro Machado, Uruguaiana e Rio Pardo. Essas notícias foram divulgadas sem destaque pelos jornais de Porto Alegre, quase sempre em pequenas notas, nas páginas internas das publicações. ${ }^{15}$

De maneira semelhante ao que ocorreu na campanha de 1934, essa também foi marcada pela violência. Os jornais destacaram relatos de espancamentos de eleitores, de proibições de comícios no interior, de homens armados impedindo reuniões e denúncias de autoridades estaduais e municipais arrebatando títulos eleitorais de eleitores para que não votassem nas eleições. A violência na campanha de 1935 foi tema constante nas edições dos jornais consultados, com matérias quase diárias nas edições de novembro. O Correio do Povo, por exemplo, destacou a ocorrência, no interior do estado, de "distúrbios com o fim de impedir ou dificultar ao eleitorado o exercício do voto" (CORREIO DO POVO, 1935, p. 11) e todos os jornais deram ênfase a um caso ocorrido em São Sebastião do Caí, no qual inúmeros processos eleitorais desapareceram.

O dia de votação em Porto Alegre é descrito como tendo ocorrido na mais absoluta ordem, sem um único incidente. foram utilizadas as palavras "ordem", "disciplina" e "tranquilidade" para descrever o dia da eleição na cidade. Mais uma vez o aspecto de ordem foi o tema selecionado pelos editores dos jornais para ser o ponto central das imagens que retratam mulheres. Chama a atenção que, entre as imagens escolhidas 
para ilustrar o pleito, não mais se encontram imagens de mulheres idosas e pouco atraentes, o que parece denotar que não mais se estranhava a presença de mulheres no mundo político e eleitoral.

Destaca-se que nesse pleito houve a eleição de uma mulher, a médica Rita Lobato, na cidade de Rio Pardo. O Diário de Notícias divulgou sua eleição sem destaque, tal como se percebe na seguinte nota publicada no jornal:

RIO PARDO, 23 - com a apuração das 23 seções eleitorais deste município, o resultado final do pleito de 17 [sic] do corrente foi o seguinte: Para prefeito [...]. Para vereadores obtiveram votação preferencial os seguintes candidatos: Ernesto Protasio Wunderlich, liberal, 1849 votos; Darci Porto Bandeira, 392; Artur Taurino de Rezende, 435, Rafael Porto Bandeira, 449, dra. Rita Lobato de Freitas, 523 votos, pertencendo todos eles à Frente Única; Salustiano Silveira, integralista, 21 votos (DIÁRIO DE NOTÍCIAS, 1935, p. 7).

A forma que o jornal escolheu para divulgar essa novidade leva a concluir que seus editores preferiram não dar ênfase a essa inédita conquista feminina. Já o Diário de Notícias somente noticiou a apuração da eleição na cidade de Rio Pardo, sem destacar que uma mulher havia conseguido ser eleita pela primeira vez no estado para ocupar um cargo eletivo. ${ }^{16}$

\section{Considerações finais}

A pretensão desse artigo foi a de dar visibilidade à participação inédita das gaúchas nas eleições da década de 1930. Buscou-se dados em quatro jornais publicados em
Porto Alegre para (re)contar essa história. Em todas as eleições analisadas os jornais procuraram dar destaque ao clima de ordem, cordialidade, moralidade e civilidade que a inédita presença feminina impôs ao pleito. O lado pitoresco e inusitado da participação feminina nas seções eleitorais também não foi esquecido e todos os periódicos acentuaram que as seções eleitorais estavam "perfumosas", "ordeiras", "repletas de crianças", "engraçadas", "barulhentas", etc. Outro dado a destacar é que o número de eleitores vinha crescendo ano a ano, pelo menos na capital do estado do Rio Grande do Sul e a presença do "elemento feminino" passou de inusitada, na primeira eleição, para corriqueira na de 1935. Pela descrição encontrada nos jornais, que destacavam a violência das campanhas eleitorais municipais, o fato de algumas mulheres terem se candidatado a vereadoras em cidades do interior do estado também deve ser mencionado.

Em todas as eleições, não importando se fossem federais, estaduais ou municipais, percebeu-se que os periódicos procuraram dar mais ênfase aos fatos ocorridos em outros estados e municípios do que em comentar os fatos ocorridos na capital e na sede de suas respectivas redações, Porto Alegre. Nos anos que separam a primeira participação feminina no pleito eleitoral de 1933 até as eleições municipais de 1935, a presença feminina no mundo público, antes restrito aos homens, estava começando a ser percebida como rotineira e sua legitimidade já não era mais contestada. Algumas mulheres estavam se candidatando aos cargos eletivos no RS e participando de agremiações políticas bem como ofereciam apoio ao candidato 
de sua preferência. Em 1937 essa sequência foi interrompida por um golpe de estado e a implantação de uma ditadura no Brasil, no qual todos os brasileiros, homens e mulheres, viram-se impedidos de participar efetivamente do mundo político e as eleições foram canceladas. De toda a forma é importante salientar que se as mulheres estavam fora do jogo político até o início do século XX, a partir de 1932 elas foram reconhecidas na sua luta em prol da igualdade jurídica com os homens. A "prenda", a mulher gaúcha, não ficou de fora dessa luta e mostrou sua efetiva participação no mundo público e político.

\section{Abstract}

The aim of this article is to elucidate the participation of women of Rio Grande do Sul in the first three elections of the New Republic in 1930's. More than pointing the unprecedented participation of citizens of Rio Grande do Sul in the election campaign this article wants to highlight the effective participation policy women at the time. For this data demand in major newspapers published in Porto Alegre: Correio do Povo, Diário de Notícias, Jornal da Manhã and A Federação.

Keywords: Elections. Press. Women.

\section{Resumen}

Se pretende aclarar en ese texto, la participación de las mujeres de Río Grande do Sul, en las tres primeras elecciones de la Nueva República, en la década de 1930. Más de señalar la participación sin precedentes de los ciudadanos de Río Grande do Sul, en la campaña electoral, esse texto quiere poner de relieve la participación efectiva de las mujeres en la época. Por esta demanda se consultará los principales periódicos publicados en Porto Alegre: Correio do Povo, Diário de Notícias, Jornal da Manhã y A Federação.

Palabras clave: Elecciones. Prensa. Mujeres.

\section{Notas}

1 A pesquisa foi financiada pelo Fundo Municipal de Apoio à Produção Artística e Cultural de Porto Alegre - Fumproarte, vinculado à Secretaria da Cultura da prefeitura de Porto Alegre. Recursos obtidos por intermédio do concurso Décio Freitas, Edital 19/2011. Também fez parte da equipe de trabalho a historiadora Juliana Sommer, a quem agradeço o empenho e a solidariedade.

2 O Decreto $\mathrm{n}^{\mathrm{O}}$ 3029, de 9 de janeiro de 1881, mais conhecida como Lei Saraiva, reformou a legislação em vigor no Brasil e restringiu o direito ao alistamento eleitoral aos cidadãos alfabetizados e que pudessem comprovar renda mínima anual de 200 mil réis. A lei também permitia o alistamento dos "habilitados com diplomas científicos ou literários, de qualquer faculdade, academia, escola ou instituto nacional ou estrangeiro, legalmente reconhecidos." Disponível em: <http://www2. camara.leg.br/legin/fed/decret/1824-1899/ decreto-3029-9-janeiro-1881-546079-publicacaooriginal-59786-pl.html>. Acesso em 25. fev. 2013.

3 Dados coletados nos jornais da época e no fundo da Federação Brasileira pelo Progresso Feminino sob a guarda do Arquivo Nacional, no Rio de Janeiro.

4 Foram consultadas todas as edições encontradas entre os meses de abril e maio de 1933, setembro e outubro de 1934 e outubro e dezembro de 1935 dos jornais Correio do Povo, Diário de Notícias, Jornal da Manhã e A Federação. Os periódicos foram pesquisados em: Museu Hipólito José da Costa, Arquivo Histórico de Porto Alegre Moyses Velinho, Acervo de Jornais e Pesquisa Correio do Povo. Todas as matérias citadas ao longo do texto tiveram sua grafia atualizada. Em nenhum momento, a imprensa foi considerada como fonte isenta, pois "cada jornal vai construindo uma visão de mundo específica 
e diferente. [...] o discurso jornalístico produz leituras do mundo, isto é, se temos consciência de que ele interpreta (e, até mesmo produz) os acontecimentos" (MARIANI, 1999, p. 103). Que fique claro que sempre se procurou perceber a diferença de olhar de cada periódico consultado sobre os mesmos fatos narrados e quanto à exposição da participação feminina nas eleições.

5 Nessas eleições, o Partido Republicano Liberal conquistou treze vagas e a Frente Única Gaúcha, somente três. A Liga Eleitoral Católica (LEC) apoiou os candidatos do PRL, graças a um compromisso formal assumido pelo partido situacionista de introduzir em seu programa os "pontos mínimos" estabelecidos pela LEC, cujos objetivos eram: o ensino religioso facultativo nas escolas, a assistência religiosa aos soldados e marinheiros bem como ter apoio do partido para impedir a legalização do divórcio no Brasil.

6 Sobre o nome da cidade de Cachoeira, em 1933, quando ocorreram os fatos narrados no artigo a cidade era assim referida, somente mudou o nome no ano de 1944, para não haver problemas burocráticos entre o município e a cidade de Cachoeira, no estado da Bahia, quando, então, passou a sua denominação para Cachoeira do Sul.

7 Na contracapa dessa mesma edição, A Federação menciona a participação das mulheres no pleito do Distrito Federal (RJ).

8 Todos os jornais consultados deram ênfase maior às eleições que ocorreram no estado bem como dedicaram mais espaço para noticiar os episódios ocorridos no interior do estado do que na capital, Porto Alegre. Nesse sentido o Correio do Povo, por exemplo, publicou 31 matérias sobre a participação feminina nos municípios do interior do estado e somente nove sobre Porto Alegre, tendência também percebida nos outros jornais.

9 De modo semelhante ao ocorrido na eleição de 1933, o PRL elegeu mais deputados do que a Frente Única: foram eleitos 13 deputados federais e 21 deputados estaduais do PRL contra 7 deputados federais e 11 deputados estaduais da Frente Única. Tal como informa Maria Izabel Noll e Hélgio Trindade: “a divisão de votos com a FU [Frente Única] é um aspecto a ser considerado nos totais eleitorais de 1934 do PRL, pois a existência de outras legendas, mesmo sem constituir-se em ameaça a dominância do partido oficial, contribui para diminuir o impacto de sua votação" (2004, p. 73). Também concorreram a uma vaga, candidatos avulsos da Liga Eleitoral Proletária e da chapa Trabalhador, ocupa o teu posto.

10 Flores da Cunha foi eleito governador em abril de 1935, cargo que ocupou até 1937, do qual foi forçado a sair por se opor ao golpe que instaurou o Estado Novo.

11 O integralismo no Brasil fez parte de uma organização de viés fascista cujo líder principal, na década de 1930, era Plínio Salgado, um dos fundadores da Ação Integralista Brasileira. Segundo Boris Fausto, "os integralistas baseavam seu movimento em temas conservadores, como a família, a tradição do país, a Igreja Católica" (2003, p. 356). Para o autor, o integralismo "se definiu como uma doutrina nacionalista cujo conteúdo era mais cultural do que econômico. [...] combatia o capitalismo financeiro e pretendia estabelecer o controle do Estado sobre a economia. Mas sua ênfase maior se encontrava na tomada de consciência do valor espiritual da nação, assentado em princípios unificadores: 'Deus, Pátria e Família' era o lema do movimento. [...] negava a pluralidade dos partidos políticos e a representação individual dos cidadãos. [...] A AIB identificava como seus inimigos o liberalismo, o socialismo, o capitalismo financeiro internacional, em mãos dos judeus. [...] atraiu para suas fileiras um número considerável de aderentes. Estimativas moderadas, calculam esse número entre $100 \mathrm{mil}$ e 200 mil pessoas no período do auge (fins de 1937)" (FAUSTO, 2003, p. 353-356). Os integralistas eram conhecidos também como camisas verdes, pois utilizavam essa cor como um uniforme.

12 O Diário de Notícias apenas apontou a criação da Seção Feminista Integralista na edição de 19 de setembro, quando publicou um discurso proferido por Aurora sobre o papel da mulher integralista na sociedade, que acentuava que: "o Integralismo muito espera da Mulher - que foi, é e será, em todos os tempos, a grande civilizadora e moralizadora das nações" (DIÁRIO DE NOTÍCIAS, 1934, p. 5).

13 Nessa última categoria é que talvez possa ser enquadrada a figura de Aurora Nunes Wagner, médica-dentista (A Federação, 30 out. 1934, p. 4).

14 Em 1933, como se viu, o eleitorado de Porto Alegre foi de pouco mais de 24 mil eleitores, contudo o Correio do Povo cometeu um equívoco ao destacar que o eleitorado feminino na capital fora maior do que na eleição de 1933, noticiado naquela data como sendo de mais de 4 mil eleitoras.

15 Pelo que se pode apurar, nenhuma mulher concorreu ao cargo de vereador na cidade de Porto Alegre.

16 Rita Lobato foi pioneira em mais de um sentido, pois também foi a primeira mulher a se formar no curso de Medicina no Brasil, ainda na época do Império. Ver mais detalhes de sua trajetória em Diva Kaastrup (1983). 


\section{Referências}

A FEDERAÇÃO, Porto Alegre, ano L, n.111, p. 1,12 maio 1933.

A FEDERAÇÃO, Porto Alegre, ano LI, n.248, p. 4, 30 outubro 1934.

A FEDERAÇÃO, Porto Alegre, ano LI, n. 263, p.2, 19 novembro 1934.

ARNAUD-DUC, Nicole. As contradições do direito. In: FRAISSE, Geneviève; PERROT, Michelle. História das mulheres no Ocidente. Vol. 4: O século XIX. Porto: Afrontamento, 1991. p. 97-137.

CARVALHO, José Murilo de. Cidadania no Brasil: o longo caminho. Rio de Janeiro: Civilização Brasileira, 2004.

CORREIODOPOVO, Porto Alegre, ano XXXIX, p. 4, 26 março 1933.

Correio do Povo, Porto Alegre, ano XXXIX, p. 1, 3 maio 1933.

CORREIODOPOVO, Porto Alegre, ano XXXIX, p. 8, 3 maio 1933.

CORREIO DO POVO, Porto Alegre, ano XL, p. 12, 6 outubro 1934 .

CORREIO DO POVO, Porto Alegre, ano XL, p. 1, 19 setembro 1934.

CORREIO DO POVO, Porto Alegre, ano XL, p. 16, 19 setembro 1934 .

CORREIO DO POVO, Porto Alegre, ano XLI, n. 266, p. 8, 16 novembro 1935.

CORTÉS, Carlos E. Política gaúcha. 1930-1964. Porto Alegre: EdiPUCRS, 2007.

DIÁRIO DE NOTÍCIAS, Porto Alegre, ano IX, n. 54, p. 1, 5 maio 1933.

DIÁRIO DE NOTÍCIAS, Porto Alegre, ano IX, n. 55, p. 3, 6 maio 1933.

DIÁRIO DE NOTÍCIAS, Porto Alegre, ano IX, n. 57, p. 5, 9 maio 1933.

DIÁRIO DE NOTÍCIAS, Porto Alegre, ano X, n. 171, p. 5, 19 setembro 1934.
DIÁRIO DE NOTÍCIAS, Porto Alegre, ano XI, p. 7, 24 novembro 1935.

FAUSTO, Boris. História do Brasil. São Paulo: Edusp, 2003.

JORNAL DA MANHÃ, Porto Alegre, ano III, n. 174, p 8, 5 maio 1933.

JORNAL DA MANHÃ, Porto Alegre, ano III, n. 181, p. 10, 13 maio 1933.

JORNAL DA MANHÃ, Porto Alegre, ano IV, n. 299, p. 7, 3 outubro 1934.

JORNAL DA MANHÃ, Porto Alegre, ano IV, n. 310, p. 1, 16 outubro 1934.

KAASTRUP, Diva Machado Pereira. A mulher na medicina. Porto Alegre: Martins Livreiro, 1983.

KÜHN, Fábio. Breve história do Rio Grande do Sul. Porto Alegre: Leitura XXI, 2004.

MARIANI, Bethânia. Sobre um percurso de análise do discurso jornalístico: a Revolução de 30. In: INDURSKY, F.; FERREIRA, M. (Org.). Os múltiplos territórios da análise do discurso. Porto Alegre: Sagra Luzato, 1999. p. 102-130.

MONTEIRO, Charles. Porto Alegre e suas escritas: histórias e memórias da cidade. Porto Alegre: EdiPUCRS, 2006.

MORAES, Maria Lygia Quartim de. Brasileiras: cidadania no feminino. In: PINSKY, Jaime; PINSKY, Carla B. (Org.). História da cidadania. São Paulo: Contexto, 2003. p. 495-515.

NOLL, Maria I.; TRINDADE, Hélgio. Estatísticas eleitorais do Rio Grande da América do Sul. 1823/2002. Porto Alegre: Ufrgs; Assembleia Legislativa do Estado do Rio Grande do Sul, 2004. PESAVENTO, Sandra Jatahy. História do Rio Grande do Sul. Porto Alegre: Mercado Aberto, 2002.

PETERSEN, Áurea Tomatis. Trabalhando no banco: trajetória de mulheres gaúchas desde 1920. 1999. 374 f. Tese (Doutorado em História) - Pontifícia Universidade Católica do Rio Grande do Sul, Porto Alegre, 1999. 
RUDIGER, Francisco. Tendências do jornalismo. Porto Alegre: Ufrgs, 1993.

SANI, Giacomo. Participação política. In: BOBBIO, Norberto (Org.). Dicionário de política. Brasília: Universidade de Brasília, 2000. p. 888890.

SCOTT, Joan. História das mulheres. In: BURKE, Peter (Org.). A escrita da história. Novas perspectivas. São Paulo: Unesp, 1992. p. 63-96.

SILVA, Jandira M. M. da; CLEMENTE, Ir. Elvo; BARBOSA, Eni. Breve histórico da imprensa sul-rio-grandense. Porto Alegre: Corag, 1986.

SIMÕES, Renata Duarte. Nem só mãe, esposa e professora: os múltiplos campos de atuação da mulher militante integralista. In: SIMPÓSIO NACIONAL DE HISTÓRIA DA ASSOCIAÇÃO NACIONAL DOS PROFESSORES UNIVERSITÁRIOS DE HISTÓRIA, 26, 2011, São Paulo. Anais... São Paulo: Anpuh, jul. 2011. Disponível em: <http:/ / www.snh2011.anpuh. org/resources/anais/14/1300504472_ARQUIVO_ANPUHRenataDuarteSimoes.pdf>. Acesso em: 22 maio 2013.

TORRESINI, Elizabeth W. R. Editora Globo: uma aventura editorial nos anos 30 e 40. 1988. 169 f. Dissertação (Mestrado em História da Cultura Brasileira) - Pontifícia Universidade Católica do Rio Grande do Sul, Porto Alegre, 1988. 